\title{
A agenda de pesquisa sobre editoriais jornalísticos: um mapeamento das produções acerca do tema
}

\section{Camila Mont'Alverne ${ }^{1}$}

\begin{abstract}
Resumo:O artigo tem como objetivo mapear a agenda de pesquisa nacional e internacional acerca de editoriais jornalísticos, usando a base de dados do Portal de Periódicos da Capes e da Biblioteca Digital de Teses e Dissertações do Ibict como fonte, e também procura identificar lacunas em tal produção. Após busca nos sites, selecionaram-se 110 documentos, que são analisados nas seguintes categorias: tema principal do trabalho, objetivo, tipo de documento, estrutura da produção, técnica metodológica, gêneros analisados, origem dos objetos das pesquisas, publicações brasileiras analisadas pelos trabalhos e ano da publicação. A análise revelou três preocupações centrais e mais recorrentes nas pesquisas: analisar a cobertura sobre determinado tema; examinar a influência dos editoriais em relação ao público ou a influência de certos fatores na produção jornalística; e discutir questões formais sobre o gênero. Notou-se também que a produção de teses e dissertações é escassa e há carência de estudos sobre periódicos brasileiros locais.
\end{abstract}

Palavras-Chave: Editorial. Jornalismo. Agenda De Pesquisa. Estado Da Arte. Gênero Jornalístico.

Abstract:The article aims to map national and international research about journalistic editorials. We used the databases from Capes' Portal Journals and Ibict's Theses and Dissertations Library as sources. The paper also aims to identify gaps on editorials' productions. After searching in the Portal and in the Library, 110 documents were selected. They are analyzed in the following categories: main theme of the work, objective, kind of document, works' structure, methodological technique, journalistic genre analyzed, origin of the researches' object, Brazilian publications analyzed and year of publication. The analysis revealed three main concerns in the researches: analyzing the coverage of a certain theme; examining editorials' influence over the public or the influence of some factors in journalistic production; and discussing formal questions about the genre. We noted that there are few theses and dissertations being produced and that there is a lack of studies about Brazilian local journals.

Keywords: Editorial. Journalism. Research agenda.Journalistic genre.

1 Doutoranda pelo Programa de Pós-Graduação em Ciência Política da Universidade Federal do Paraná (PPGCP/UFPR). E-mail: camilapessoa31@gmail.com 


\section{Introdução}

O editorial é um texto jornalístico institucional, no qual a empresa apresenta ao público o ponto de vista que defende. Pode ser compreendido como "a voz do jornal, sua tribuna” (BELTRÃO, 1980, p. 52), um espaço no qual os leitores buscariam informações atualizadas sobre diversos temas (ARMAÑANZAS; NOCÍ, 1996). O editorial tem a pretensão de guiar o leitor sobre a compreensão de variados assuntos, oferecendo uma maneira de interpretá-los a partir da perspectiva da empresa.

Além desta dimensão, o editorial também é um espaço no qual o jornal se coloca no debate público, afirmando suas posições e conformando a agenda de discussões, priorizando alguns temas específicos.

O editorial, além de oferecer opinião, é um agente da voz e do conteúdo do jornal. Mais que produzir opiniões, ele representa o conteúdo total do periódico; ele coloca em domínio público assuntos, eventos e ideias para consumo e discussão em um fórum democrático (HALLOCK, 2007, p. 162, tradução nossa).

O estudo sobre editoriais, para além das características do gênero ARMAÑANZAS; NOCÍ, 1996; BELTRÃO, 1980; MELO, 1985), pode ajudar a compreender as posições das empresas jornalísticas em relação a diversas temáticas (CAPELATO; PRADO, 1980; COUTINHO; MIGUEL, 2007; HALLOCK, 2007; IZADI; SAGHAYE-BIRIA, 2007; MONT'ALVERNE; MARQUES, 2013), bem como o lugar social que tais empresas atribuem a si (MORAES, 2007), dentre outras questões.

Partindo desta compreensão inicial sobre o editorial jornalístico, o objetivo do artigo é mapear a produção sobre editoriais disponível no Portal de Periódicos da Capes, fonte de pesquisa para diversas áreas do conhecimento no Brasil. Além do Portal da Capes, foram buscadas teses e dissertações na Biblioteca Digital de Teses e Dissertações do Ibict (BDTD), que permite acessar produções mais extensas que artigos. 
O trabalho também pretende identificar lacunas na pesquisa sobre editoriais, bem como compreender as principais agendas de pesquisa sobre o tema. Ressalte-se a escassez de levantamentos sobre editoriais e da própria investigação científica sobre tal gênero, como será demonstrado ao longo do trabalho. Isto mostra a importância deste tipo de trabalho, que, além de sistematizar parte do que já foi produzido sobre o assunto, oferece apontamentos para pesquisas futuras.

A próxima seção é dedicada a explicar as estratégias metodológicas utilizadas neste artigo. Em seguida, será apresentada a análise dos trabalhos coletados, a partir das categorias delimitadas pela pesquisa. Por fim, são feitas as considerações finais sobre os achados.

\section{Estratégias metodológicas}

Mapear a produção sobre editoriais jornalísticos apresenta, de início, uma dificuldade pela multiplicidade de sentidos do termo "editorial". As revistas científicas costumam trazer editoriais apresentando o conteúdo de suas edições, o que não interessa a este trabalho. Existem, também, pesquisas sobre mercado editorial, outro tema que não é o foco deste levantamento. Isto exigiu a leitura dos resumos dos documentos encontrados, a fim de identificar se o texto tratava realmente de editoriais jornalísticos.

Além do Portal de Periódicos da Capes e da BDTD, considerou-se trabalhar com outro portal brasileiro, o Scielo, mas a busca inicial não apresentou resultados satisfatórios. A pesquisa no Scielo oferecia textos gerais sobre Jornalismo ou editoriais de revistas científicas, mas não trouxe resultados sobre editoriais jornalísticos especificamente.

Diante de tal situação e da abrangência temática do Portal de Periódicos da Capes, optou-se por utilizá-lo como uma das fontes para este trabalho. Trabalhar com o Portal permite alcançar produções de países e de bases de dados diferentes, algo que se mostra fundamental devido à interdisciplinaridade dos estudos em Comunicação. 
A coleta do material no Portal foi feita no dia 30 de outubro de 2014 e dividida em dois momentos. Primeiro, foram pesquisados trabalhos em português, com as seguintes palavras-chave: "editorial", "Jornalismo" e "opinião". Foi encontrado um total de 71 resultados. Destes, 68 eram artigos e 3 eram teses e dissertações.

Depois, foram realizadas buscas com as palavras-chave em inglês, para alcançar a literatura internacional. Foram utilizados os termos editorial, newspaper, opinion e journalism. Como tal busca apresentou somente 100 resultados, com 30 deles sendo artigos, foi feita uma nova pesquisa, suprimindo o termo journalism. Nela, os resultados totais ultrapassavam 20 mil textos. No entanto, grande parte deles eram artigos de jornais, o que não interessa a esta pesquisa. Assim, foram lidos os resumos apenas dos 486 artigos e das 5 teses e dissertações encontradas com tais palavras-chave, a fim de identificar quais seriam pertinentes ao levantamento.

A pesquisa na Biblioteca Digital de Teses e Dissertações (BDTD) aconteceu no dia 19 de novembro de 2014. A princípio, foram utilizados os termos editorial, Jornalismo e opinião como palavras-chave. No entanto, havia um número alto de resultados (2889, exatamente), sem tratar necessariamente de editoriais jornalísticos. Como, no caso da BDTD, não haveria a possibilidade de serem reportados editoriais de revistas científicas como resultados, utilizou-se apenas o termo editorial para a pesquisa. Com apenas um termo, foram encontrados 97 teses e dissertações.

Conforme explicado no início desta seção, os documentos encontrados não seriam, necessariamente, utilizados por este trabalho. Parte considerável dos textos classificados como artigos não se referiam a editoriais jornalísticos, mas eram editoriais de revistas científicas. Após a leitura do resumo, os documentos eram descartados ou coletados para serem analisados, de acordo com o teor deles. Ao final da coleta, 110 textos, entre artigos, teses e dissertações, compõem o corpus desta pesquisa [1].

Após contato prévio com o material e com outros artigos que propusessem fazer o estado da arte de determinado tema (CARREIRO, 2014; FERREIRA, 2002; 
RUBIM, 2008; VERMELHO E AREU, 2005), foram estabelecidas categorias a fim de organizar a análise. Embora os autores trabalhassem com outras temáticas, parte das categorias foi estruturada a partir dos artigos de Carreiro (2014) e de Vermelho e Areu (2005). Algumas, no entanto, foram elaboradas a partir das necessidades diagnosticadas com a pré-análise dos textos. As categorias utilizadas pela análise estão apresentadas a seguir:

Tema principal do trabalho: Assunto principal de qual trata o texto;

Objetivo: Objetivos da pesquisa;

Tipo de documento analisado: Tese/dissertação/artigo (VERMELHO E AREU, 2005);

Estrutura da produção: Ensaio/sistematização teórica/pesquisa empírica (VERMELHO E AREU, 2005);

Técnica metodológica: Técnicas utilizadas para chegar ao objetivo final do estudo (CARREIRO, 2014). Por exemplo: análise de conteúdo, entrevistas, surveys;

Gêneros analisados: $O$ trabalho analisa apenas editoriais ou trata de outros gêneros jornalísticos?;

Origem dos objetos das pesquisas: Países ou regiões aos quais pertence o material que compõe o corpus;

Publicações brasileiras analisadas pelos trabalhos: Periódicos brasileiros cujo conteúdo é analisado nos documentos;

Ano da publicação do trabalho: Ano em que o texto foi publicado.

Para responder a cada categoria citada acima, foram lidos o resumo e a introdução dos textos. Em alguns casos, quando todos os dados não estavam disponíveis nas seções mencionadas, procuraram-se as informações no corpo do texto, na seção correspondente [2].

\section{Análise dos dados}

A exposição dos dados se dará a partir de cada categoria. No caso do tema e objetivos, entende-se que estão fortemente ligados e, por isso, serão apresentados na mesma seção. 


\section{Tema e objetivos}

A partir da leitura dos resumos, foram identificados os temas e objetivos mais recorrentes. Serão comentados, então, tais temas e objetivos, bem como os trabalhos mais representativos, a fim de oferecer um panorama geral sobre as pesquisas realizadas.

Figura 1:Temas e objetivos

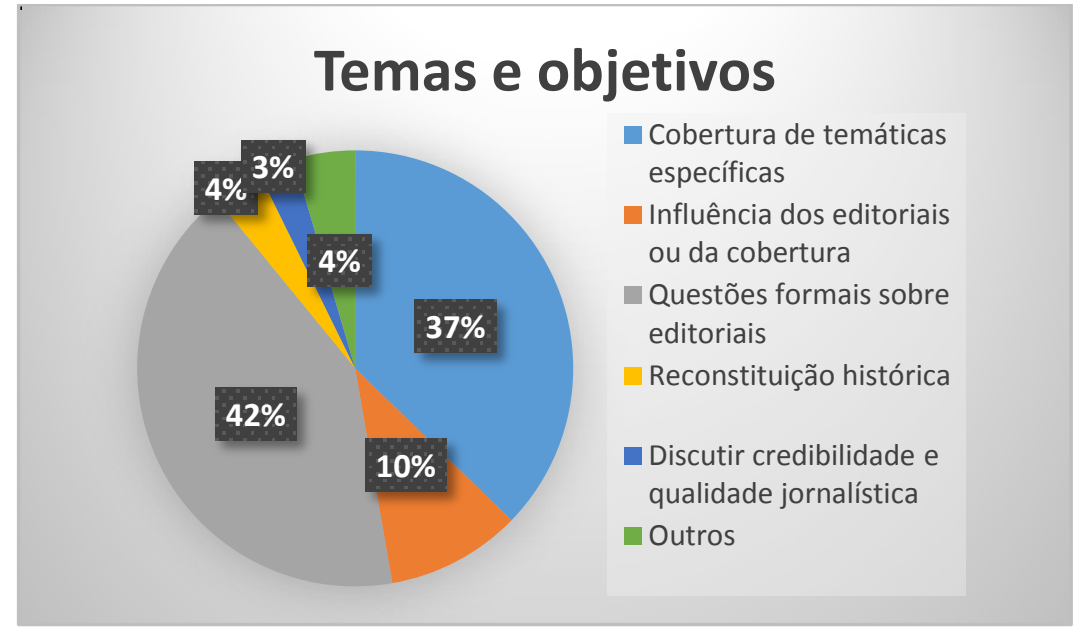

Fonte: Autora

Um primeiro objetivo frequente nos textos é analisar a cobertura sobre determinado assunto. 41 das peças analisadas têm como objetivo investigar como os jornais abordam temáticas específicas. Nestes casos, é comum que os editoriais figurem junto a outros textos, pois, nem sempre, há diferenciação entre cobertura opinativa e informativa nos trabalhos.

Alguns dos temas abordados pela análise da cobertura são questões de cunho social, como ações afirmativas (COLEMAN, 2003; PEREIRA, 2011; RICHARDSON; LANCENDORFER, 2004), prostituição (STREGA et al., 2014), assuntos feministas (ALEXANDER, 1999) bem como atentados e guerras (CAMINOS-MARCET, 2013; HERNÁNDEZ, 2010; RODRÍGUEZ, 2005; SAHLANE, 2012), representação de minorias (YAMAMOTO, 2013), a abordagem sobre AIDS (JACOBS; JOHNSON, 2007; OBIJIOFOR, 2010), sobre a regulamentação do tabaco 
nos Estados Unidos (HARRIS et al., 2009; STILLMAN et al., 2001) e sobre casamento homossexual (FULCO; MACHACEK, 2004).

Especificamente sobre o contexto brasileiro, existem trabalhos sobre cobertura da integração prevista pelo Mercosul (NUNES NETO, 2012), da representação do ensino superior no Brasil em editoriais (SILVA, 2013), acerca do discurso dos jornais sobre a implantação de ensino religioso nas escolas do Rio de Janeiro (CARVALHO, 2008), assim como sobre a noção de política construída nos editoriais (GHISLENI, 2003). Há, ainda, artigo comparando a cobertura sobre os gastos do governo FHC por jornais diferentes (FREITAS, 2011).

Alguns trabalhos dedicam-se a analisar a cobertura sobre eleições (LÓPEZ, 2007; SCHUCK, 2011) ou sobre um partido específico (RAMSAY, 1992). Questões mais específicas são abordadas em determinados artigos, como a constituição da imagem pública de Gorbatchev em editoriais (COSTA, 2007) e a forma que o Governo Bush configurou a cobertura entre o 11 de setembro e o caso de Saddam Hussein (JOHN et al., 2007).

Outro objetivo identificado entre os textos é o de analisar a influência dos editoriais ou da cobertura, seja junto aos leitores, em relação ao conteúdo informativo dos jornais ou em disputas eleitorais (HERAS-SAIZARBITORIA et al., 2011; RICHARDSON, 2005). Onze das peças analisadas trazem o objetivo mencionado. Há artigos dedicados a analisar a aceitação pública da utilização de energia solar por causa da cobertura dos jornais (HERAS-SAIZARBITORIA et al., 2011) ou o impacto dos enquadramentos dos editoriais na compreensão dos leitores sobre ações afirmativas (RICHARDSON, 2005).

A influência dos editoriais junto às decisões dos agentes políticos e dos eleitores também é tema presente nos estudos mapeados. O texto de Wright (2007), por exemplo, discute a importância de que os jornais endossem candidaturas em editoriais. Também se referindo ao período eleitoral, Dalton et al. (1992) debruçamse sobre a relação entre o conteúdo dos jornais e as preferências partidárias, procurando entender se a cobertura afeta tais predileções. Scarrow e Borman (1979) desenvolvem um estudo sobre os efeitos de endossos em editoriais no resultado das 
eleições. Já o trabalho de Hallock (2008) analisa o efeito dos editoriais junto aos agentes políticos e o quanto tais textos podem influenciar as decisões tomadas.

Outros trabalhos preocupam-se com diversas influências para a produção jornalística. O artigo de Hollifield (1999) procura investigar a influência da nacionalidade da empresa de comunicação na cobertura sobre a independência de determinados lugares. O de Branton e Dunaway (2009), por sua vez, buscam entender os fatores a influenciar o comportamento da mídia na cobertura sobre imigração. Leurer (2013) analisa quais técnicas foram usadas por organizações de enfermeiros para influenciar a adoção de enquadramentos pela cobertura sobre assuntos de interesse da classe.

Já a pesquisa de Kahn e Kenney (2002) investiga a relação entre os editoriais dos jornais e a cobertura informativa feita pelos próprios veículos. $\mathrm{O}$ artigo de Lams (2011), por sua vez, aborda as mudanças existentes entre o conteúdo ofertado pelo jornal e o concedido, anteriormente, pelas agências, além das diferenças em relação ao material proveniente da mesma fonte em periódicos diversos.

Há pesquisas, ainda, que se debruçam sobre questões formais a compor os editoriais, discutindo estratégias discursivas a compor os textos do gênero e as mudanças pelas quais ele vem passando e pelas quais pode passar. Em 46 dos textos analisados, encontram-se tais questões.

Existem trabalhos focados em identificar a construção retórica dos editoriais, a exemplo da dissertação de Garrido (2011), que buscou identificar e descrever os recursos discursivos e enunciativos utilizados pelo jornal Bom Dia Bauru na construção de suas opiniões, além de detectar, identificar e caracterizar as vozes presentes nos discursos que emanam desses textos.

$\mathrm{O}$ enfoque em questões retóricas, enunciativas ou argumentativas dos editoriais é frequente em diversas teses e dissertações brasileiras analisadas neste trabalho. A dissertação de Leal (2012) preocupa-se com o discurso argumentativo nos editoriais. Também com uma discussão sobre argumentação, Ribeiro (2013) estuda os operadores argumentativos e o papel desempenhado por eles na produção de 
sentido de editoriais do jornal O Globo. Parreira (2006) aborda operadores argumentativos, analisando o uso deles na construção de editoriais da Folha de S. Paulo, de o Estado de Minas e de O Globo. Campos (2008), por sua vez, debate sobre discurso argumentativo, examinando quais estratégias argumentativas são utilizadas em editoriais do jornal O Globo.

Preocupando-se com questões estruturais do gênero, Hernández (2010) propõe descrever as ferramentas formais e linguísticas com as quais os jornais estruturam os editoriais. Mac Cord (2008) observa a inserção do discurso outro em editoriais, a fim de entender a tensão presente nos textos pela falta de pessoalidade e de assinatura. Hermann e Rubenfeld (1985) desenvolvem uma pesquisa a fim de apontar as propriedades léxicas necessárias para compreender se uma palavra representa fato ou opinião.

Já Ansary e Babaii (2009) se esforçam em identificar a estrutura retórica de editoriais, caminho semelhante ao traçado por Le (2004). A autora busca mostrar como o periódico constrói a própria autoridade nos editoriais. O trabalho de Discini (2003), por sua vez, compara o ethos construído pelos jornais em editoriais e em charges.

A tese de Bertasso (2014) também trabalha com tal noção, procurando compreender o ethos discursivo das revistas semanais construído em capas e editoriais. Este é o único documento analisado neste artigo que analisa somente revistas semanais.

A discussão sobre as mudanças pelas quais os editoriais passaram ou estão sujeitas a passar aparece, em certos momentos, ligada à ideia de alterações nas próprias páginas de opinião (BENFIELD, 1995; HASLANGER, 1995; LAWRENCE, 2007; OPPEDAHL, 2007; SHEPPARD, 1995; VOGEL, 2007; WINSHIP, 1993). Há, ainda, preocupação em discutir a função e a importância dos editoriais (GAUSLAA et al., 1997), bem como debater a importância da investigação jornalística para a escrita de editoriais (DAVIS, 1996).

Alguns artigos abordam a estrutura do gênero editorial por um viés de aprendizado da escrita do texto (ZADROZNY, 2007; PIMENTEL, 2004), como o de Davenport (2008), que discute sobre como aumentar o impacto dos editoriais. 
Outros quatro trabalhos preocupam-se em traçar uma reconstituição histórica (RYSTROM, 2014; FITZGERALD, 2004). Um exemplo é o artigo de Hallock (2008) mapeando os temas abordados em diversos editoriais e em diálogo com o de Semion (1996), dedicado a identificar mudanças no conteúdo dos editoriais entre 1946 e 1996.

Existem, ainda, três artigos preocupados com a qualidade e com a credibilidade jornalística. Ruether (1994) compara a qualidade da cobertura nos EUA e na Nicarágua. Já Fitzgerald (1997) discute sobre a qualidade do conteúdo editorial e do publicitário nos jornais, enquanto a dissertação de Lisboa (2012) investiga os valores associados pelo leitor à credibilidade jornalística.

Cinco trabalhos não se encaixam nos grupos identificados acima. O primeiro deles, de Chen e Shughart (2003), analisa a união (JOA) formada por dois jornais dos EUA. O de Adams e Lewis (2002) compara a readability de colunas de negócios com a de outras seções dos periódicos. Em seguida, Beckwith (2009) aborda assuntos como uma Universidade cristã e a relação com a fé, passando pelo conteúdo de jornais, enquanto Blevens (1996) discute a diminuição do interesse dos alunos por cursos sobre Jornalismo opinativo. Por fim, Gallman (2002) discute sobre a participação de minorias nas páginas de opinião.

\section{Tipo de documento analisado}

A maioria dos documentos analisados, 86, eram artigos. Foram encontradas, ainda, 20 dissertações e 4 teses. As dissertações e teses catalogadas foram todas desenvolvidas por pesquisadores brasileiros. A quantidade de artigos e sua predominância em relação a trabalhos mais extensos indicam que o estudo sobre editoriais ainda há espaço para novas discussões e abordagens, especialmente para pesquisas de fôlego sobre o assunto. 
Figura 2: Tipo de documento analisado

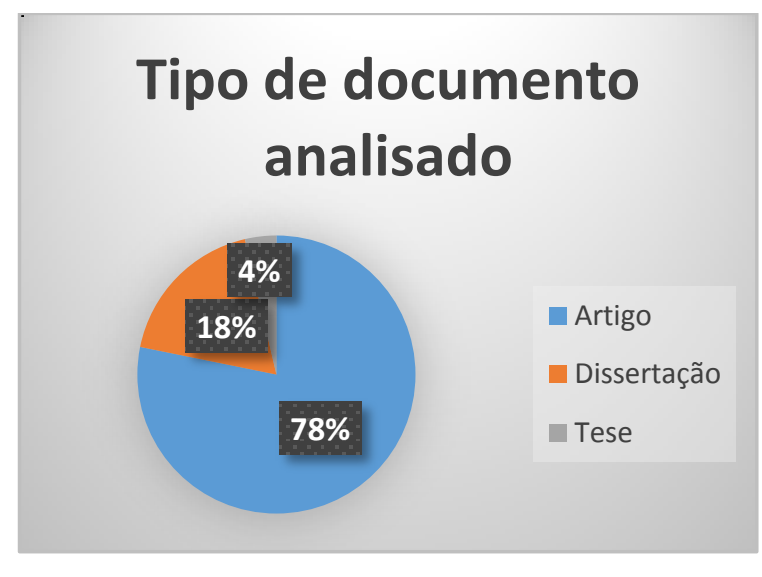

Fonte: Autora

\section{Estrutura da produção}

Figura 3: Estrutura da produção

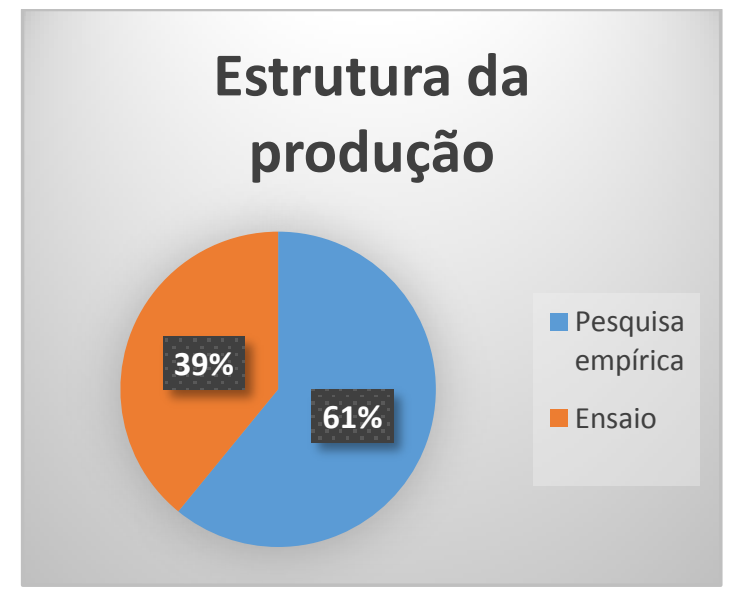

Fonte: Autora

Os resultados sobre a estrutura da produção dos trabalhos analisados corroboram a ideia de que os editoriais jornalísticos não foram explorados fartamente, em especial, por pesquisas empíricas e em sistematizações teóricas. Em números absolutos, 67 dos documentos analisados são pesquisas empíricas, enquanto 43 deles são ensaios.

Dentre os ensaios, são abordadas questões da rotina jornalística na página de opinião, a qualidade da cobertura oferecida pelos jornais ou uma reconstituição 
histórica de editoriais ou periódicos. As pesquisas empíricas preocupam-se com assuntos como a cobertura de determinados eventos e temas ou a influência dela em relação ao comportamento (eleitoral ou não) dos cidadãos e agentes políticos. Entre as teses e dissertações, em especial, é frequente a discussão sobre questões estruturais ou linguísticas dos editoriais.

Os ensaios, portanto, examinam questões mais próximas da forma de produção do material jornalístico, enquanto as pesquisas empíricas abordam o produto e os efeitos dele junto à audiência.

É notável, ainda, o fato de não ter sido encontrada nenhuma sistematização teórica sobre o assunto entre os trabalhos analisados. Os editoriais jornalísticos são tratados mais pelo viés da pesquisa empírica e ensaística, sem grande preocupação com sistematizar o conteúdo já produzido na área, os conceitos mais utilizados ou os principais achados.

\section{Técnica metodológicas}

Figura 4: Tipo de documento analisa

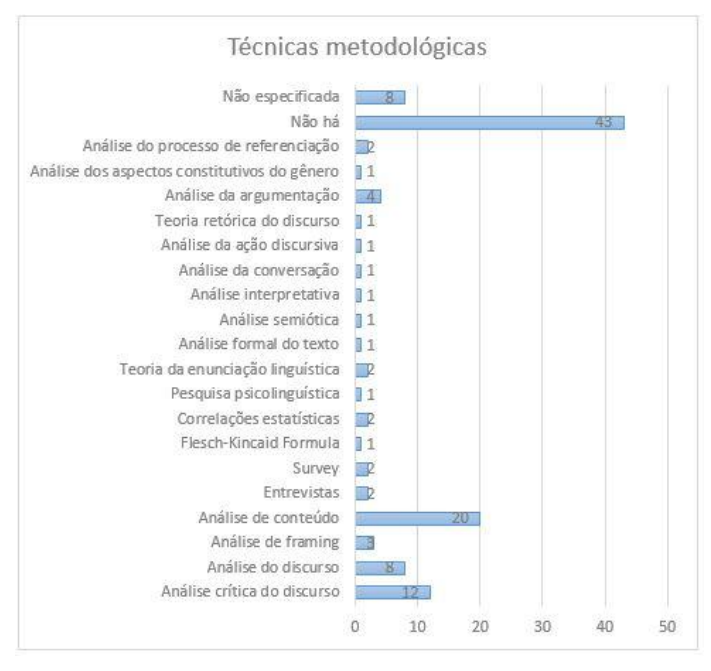

Fonte: Autora

Nos documentos analisados, encontram-se diversas técnicas metodológicas, com predomínio de análise de conteúdo ou do discurso - seja a análise crítica do discurso ou outras abordagens. Como a identificação da técnica metodológica utilizada se deu a partir da explicitação dela no trabalho, foram 
categorizadas como diferentes a análise do discurso e a análise crítica do discurso, por exemplo.

As técnicas utilizadas espalham-se por diversas opções metodológicas e algumas são utilizadas em conjunto com outras estratégias, a exemplo de artigo que combina análise de conteúdo, entrevistas e análise crítica do discurso (HERASSAIZARBITORIA et al., 2011) ou daquele unindo análise de conteúdo e de framing (BROCK; LARSEN, 2005).

A diversidade de técnicas metodológicas encontradas indica a multiplicidade de áreas que desenvolvem estudos sobre editoriais. Estudos da área de Letras ou Linguística adotam estratégias como a análise do processo de referenciação, dos aspectos constitutivos do gênero, da argumentação, da ação discursiva, da conversação, bem como análise interpretativa, semiótica e abordagem próxima da retórica, com a teoria retórica do discurso e a da enunciação linguística. Há, ainda, a técnica que conjuga elementos de psicologia e linguística, propondo uma pesquisa psicolinguística.

A análise do discurso, assim como a análise crítica do discurso, é utilizada por estudos em Letras, mas também na área de Comunicação. As pesquisas em Comunicação adotam técnicas como análise de conteúdo e de framing, bem como realizam entrevistas e surveys com os pesquisados. As correlações estatísticas também aparecem em estudos de Comunicação, em artigos que analisam uma cobertura específica de jornais (NAGEL; ERIKSON, 1966-67; STILLMAN et al., 2001). O alto número de artigos nos quais não há técnica metodológica se dá pela recorrência de ensaios no material analisado. A quantidade de ensaios demonstra a importância do gênero editorial, especialmente, porque grande parte de tais trabalhos foi publicada por jornalistas em revistas dedicadas a discutir a atividade. Por mais que a aproximação com o gênero, nestes casos, nem sempre se dê pelo interesse acadêmico, a discussão se mostra relevante para o próprio campo do Jornalismo.

Definir com clareza as estratégias metodológicas, porém, se mostra um problema para alguns autores quando se leva em conta a quantidade de peças nas quais a técnica adotada não é especificada. 
A variedade de técnicas metodológicas encontradas, mais que indicar a diversidade de áreas desenvolvendo pesquisa acerca de editoriais, segue uma realidade dos objetos da comunicação, que é um campo de estudos híbrido. A pesquisa na área é, quase necessariamente, interdisciplinar, tendo em vista que o referencial teórico-metodológico provém de diversas fontes, compelindo o pesquisador a um diálogo com outras áreas, como a Linguística, a Sociologia ou a Ciência Política, para citar somente algumas.

\section{Gêneros analisados}

O objetivo desta categoria é investigar se as pesquisas analisavam apenas editoriais ou também textos de outros gêneros jornalísticos - ou até outros documentos, como resultados de surveys. 62 dos 110 trabalhos (56\%) tratavam também de peças de outros gêneros textuais, enquanto os 48 (44\%) restantes preocupam-se apenas com editoriais.

Figura 5: Gêneros analisados

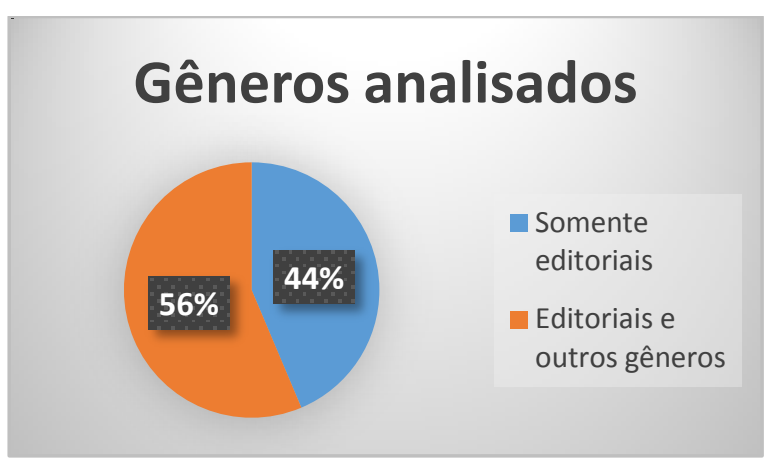

Fonte: Autora

Os resultados indicam que parte considerável dos trabalhos não aborda as peculiaridades do editorial como gênero, nem faz distinção entre jornalismo informativo ou opinativo, tendo em vista que pode trabalhar com notícias, reportagens, editoriais, colunas e cartas do leitor em uma só pesquisa. O foco dos textos, portanto, nem sempre é o editorial. Tais textos entram como dados a mais na pesquisa, sem discussão específica sobre as particularidades do gênero.

No caso dos trabalhos que tratam somente de editoriais, a preocupação em discutir o gênero de forma mais detida é uma constante, a exemplo da dissertação de 
Ghisleni (2003), examinando a noção de política construída em editoriais ou a de Chagas (2010), dedicada a examinar estratégias linguísticas para evidenciar autoria em tais textos.

\section{Origem dos objetos das pesquisas}

Os dados sobre a origem dos objetos das pesquisas mostram a predominância de trabalhos realizados tendo como foco publicações dos Estados Unidos, com 60 textos analisando produtos do país [3]. Em seguida, aparece o Brasil, com 29 trabalhos. O Canadá aparece em cinco trabalhos, enquanto diversos países europeus - e dois trabalhos que tratam da região como um bloco -, figuram com alguns artigos publicados sobre produtos locais. A América Latina tem, além dos objetos brasileiros, pesquisas sobre publicações da Nicarágua, da Colômbia e do Paraguai, enquanto a África tem objetos de Gana e da Nigéria. Por fim, a Ásia aparece em trabalhos analisando periódicos do Japão, Paquistão, Índia e China.

Figura 6: Origem dos objetos das pesquisas

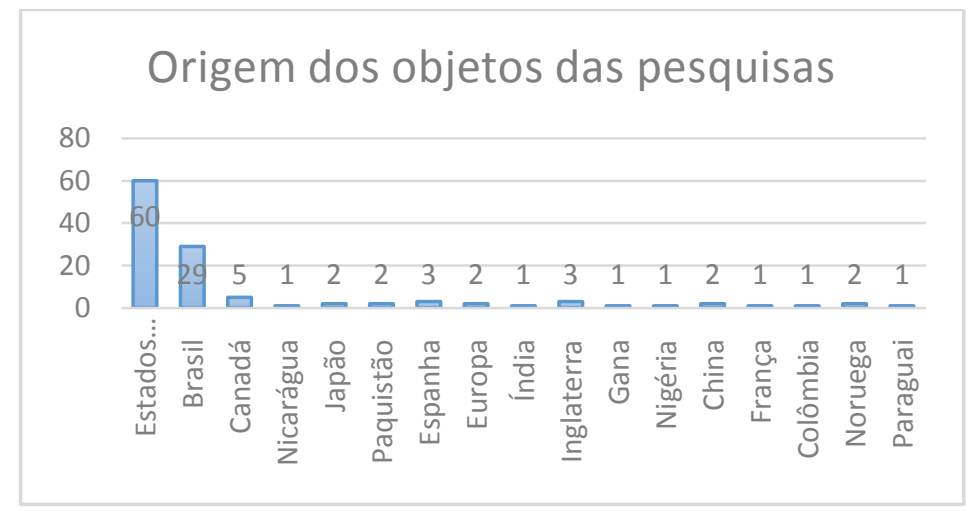

Fonte: Autora

Enquanto os trabalhos internacionais são todos artigos, sejam ensaios ou pesquisas empíricas, grande parte das pesquisas brasileiras analisadas (23 delas) são dissertações ou teses. Isto aconteceu por uma das bases de pesquisa ter sido uma biblioteca brasileira de teses e dissertações. No entanto, chama atenção que poucos artigos nacionais sobre editoriais tenham sido encontrados no Portal de Periódicos da Capes, até porque a tendência é que pesquisas mais extensas sejam transformadas em 
artigos. O quadro pode indicar internacionalização incipiente das publicações brasileiras nesta área de pesquisa.

\section{Publicações brasileiras analisadas pelos trabalhos}

Nesta seção, o objetivo é mapear as publicações brasileiras que foram estudadas por trabalhos sobre editoriais. Durante análise das pesquisas para este artigo, também foram identificados os jornais internacionais estudados. Porém, diante da quantidade de resultados e da pesquisa de dissertação da autora, que trabalha com editoriais de jornais brasileiros, optou-se por quantificar apenas os dados referentes à realidade do Brasil.

Figura 7: Publicações brasileiras analisadas pelos trabalhos

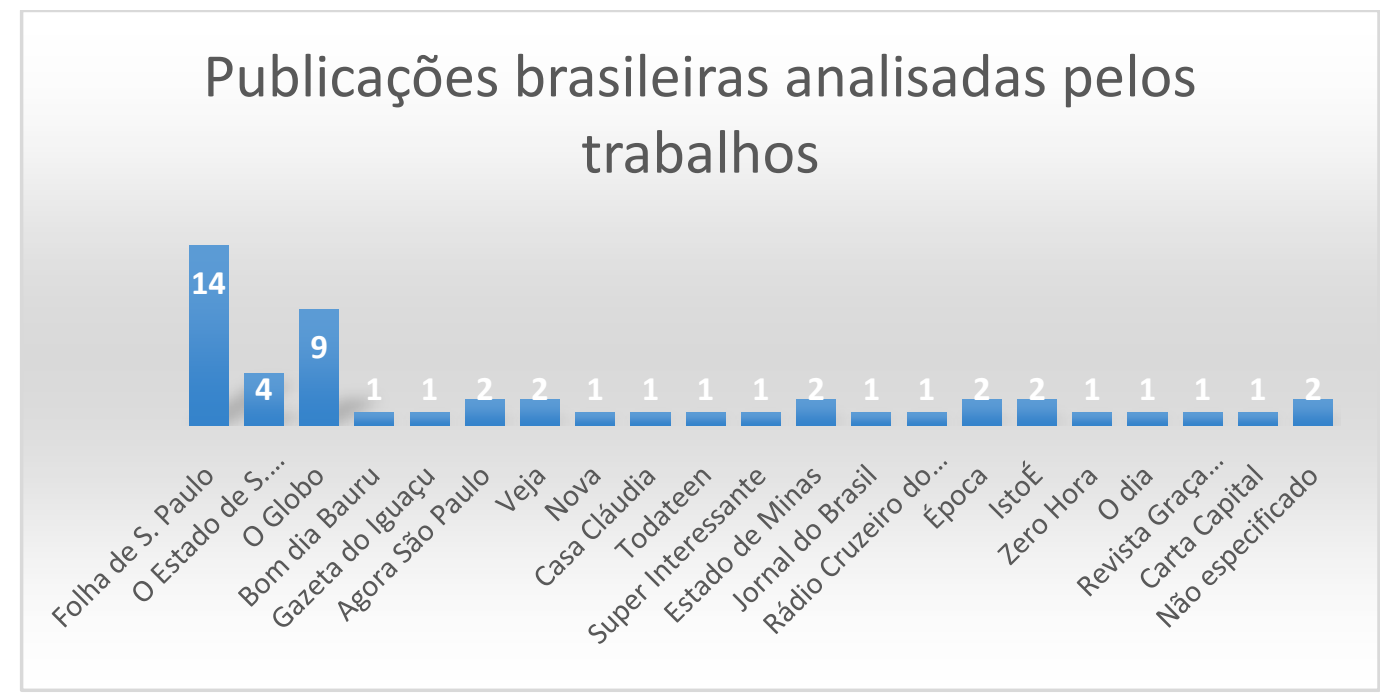

Fonte: Autora

Grande parte das publicações analisadas estão no eixo Rio-São Paulo, especialmente quando se trata dos jornais. A Folha de S. Paulo é o periódico mais estudado pelas pesquisas. Dos 29 trabalhos brasileiros examinados neste artigo, o jornal da família Frias figura em 14 deles (48,3\%). Em seguida, O Globo é objeto de 9 trabalhos (31\%). Outros três periódicos paulistas e um carioca são analisados. São eles: O Estado de S. Paulo (13,8\%), Agora São Paulo (6,9\%), Bom Dia Bauru (o,29\%) e o carioca Jornal do Brasil (0,29\%). Além dos citados, a Rádio Cruzeiro do Sul, que 
tem editorial estudado em um dos trabalhos, também é paulista. O Estado de Minas é objeto de dois $(6,9 \%)$ estudos.

Duas publicações do Sul do Brasil são estudadas, cada uma figurando em uma pesquisa. São elas os jornais Gazeta do Iguaçu e Zero Hora. As regiões Norte e Centro-Oeste não contam com nenhuma publicação analisada, enquanto o Nordeste conta com o jornal O Dia, de Teresina, também figurando em uma pesquisa.

É curioso que nem mesmo jornais de Brasília, a capital federal, sejam investigados pelas pesquisas estudadas neste artigo. Levando em conta que "o editorial é o instrumento de influência máxima de que dispõe um meio" (LAVEDÉZE, 1979, p. 284 apud ARMAÑANZAS; NOCÍ, 1996, p. 65, tradução própria), chama a atenção o fato de não terem sido encontrados trabalhos analisando editoriais dos jornais da capital do país, onde há mais proximidade com os agentes políticos do Brasil. Isto indica a influência dos jornais do Sudeste na conformação da agenda pública de discussões.

A predominância de estudos sobre a Folha de S. Paulo e O Globo apontam a relevância das publicações no cenário nacional, inclusive pela tiragem de ambos, que estão entre as maiores do Brasil [4] e pelo fato de serem quality-papers.

Sobre O Estado de S. Paulo, chama a atenção que figure em apenas quatro pesquisas dentre as analisadas. Além de ocupar uma posição semelhante àquela de $\mathrm{O}$ Globo e Folha no cenário brasileiro, o periódico dos Mesquita tem uma postura particular nos seus editoriais em relação a outras empresas do Brasil: o Estadão costuma endossar candidaturas a Presidente.

Outro dado revelado pelo mapeamento é a carência de estudos sobre editoriais em periódicos locais. Isto pode ser explicado, em alguma medida, pelo próprio alcance de tais publicações, que pode ser baixa até mesmo em relação ao estado ao qual pertencem. Dentre os cinco jornais brasileiros de maior tiragem, nenhum está fora do Sudeste [5].

Poucos estudos abordam revistas, como mencionado na seção de tema e objetivos. Tal cenário é, de certa forma, esperado, pela própria configuração específica das revistas. Ao contrário dos jornais, que trazem a diferenciação entre conteúdo informativo e opinativo, parte significativa dos textos de revistas - 
especialmente, semanais - são editorializados, produzindo uma mescla entre opinião e informação. Embora o conteúdo informativo do jornal não esteja isento de perspectivas e da opinião da empresa e dos profissionais, o gênero que, oficialmente, representa as posições do periódico é o editorial. No caso das revistas, as reportagens também estão permeadas pelas ideias da publicação, que não costuma extrair - nem se preocupar demais em fazê-lo - as opiniões dos textos. O contrato do leitor com a revista é diferenciado. Daí, também, o papel dos gêneros jornalísticos sofrer alteração de acordo com o produto.

\section{Ano da publicação do trabalho}

Figura 8: Ano da publicação do trabalho

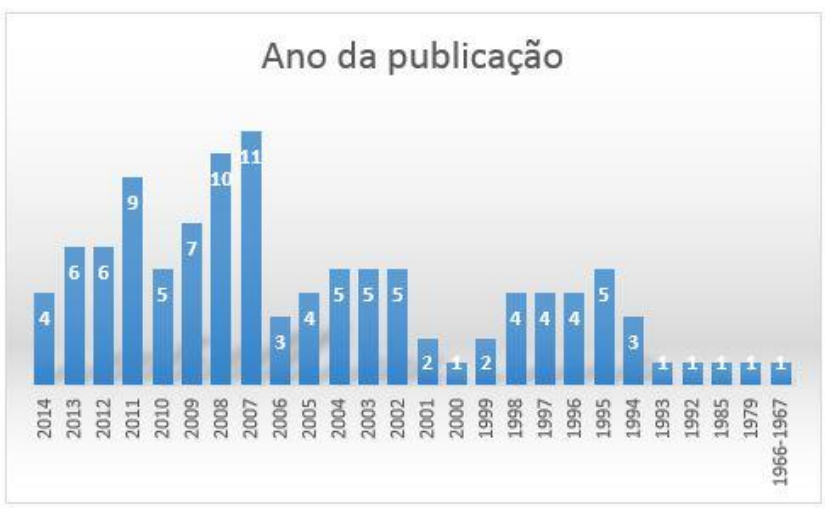

Fonte: Autora

O primeiro trabalho abordando editoriais jornalísticos encontrado foi publicado na segunda metade dos anos 60. Mais de dez anos depois, em 1979, aparece outra pesquisa. A década de 80 também contribui com um artigo. A partir de 1992, há, pelo menos, uma publicação sobre editoriais a cada ano, com pico de trabalhos publicados em 2007. No Brasil, os primeiros trabalhos encontrados no levantamento feito para este artigo são de 2003 (DISCINI, 2003; GHISLENI, 2003). Já pesquisas de maior fôlego, como teses e dissertações, aparecem com mais frequência a partir de 2006 (BARROS, 2014; BERTASSO, 2014; CARVALHO, 2008; CHAGAS, 2010; GARRIDO, 2011; GONÇALVES SEGUNDO, 2011; LEAL, 2012; LISBOA, 2012; MAC CORD, 2008; NUNES NETO, 2012; ODA, 2008; OLIVEIRA, 
2009; PAIERO, 2011; PARREIRA, 2006; PEREIRA, 2008; PEREIRA, 2011; RIBEIRO, 2013; SABAINI, 2012; SILVA, 2013; VIEIRA, 2009; ZAGO, 2008).

\section{Considerações finais}

O artigo teve por objetivo mapear a pesquisa sobre editoriais jornalísticos no Brasil e em periódicos internacionais, a fim de fazer um panorama sobre o que já foi produzido sobre o assunto. Descobriram-se três preocupações principais nas pesquisas, que norteavam os objetivos traçados. São elas: analisar a cobertura sobre determinado tema; examinar a influência dos editoriais em relação ao público ou a de certos fatores na produção jornalística; e discutir questões formais sobre o gênero.

No Brasil, parte significativa das teses e dissertações desenvolvidas aborda o editorial a partir de uma perspectiva da Linguística ou dos estudos em Letras, procurando identificar as estratégias para construção dos textos, por exemplo. A análise da cobertura sobre um assunto específico é mais rara no país, bem como a investigação sobre a influência dos editoriais junto ao público, que não conta com nenhum estudo brasileiro listado nas bases de dados consultadas.

Identifica-se, a partir dos trabalhos analisados, que há preocupação com o papel político dos editoriais, embora concentrado em interesses específicos, como os citados acima. É pouco abordado, por exemplo, o fato de o editorial atuar como construtor da realidade e de imagens públicas.

Pouco é discutida a relação entre o conteúdo dos editoriais e a cobertura informativa dos jornais ou se há reverberação das posições assumidas no texto institucional na produção noticiosa dos periódicos. Apenas um artigo analisado traz tal preocupação (KAHN; KENNEY, 2002) e ele não analisa a realidade brasileira. Há carência, ainda, de pesquisas explorando a influência do editorial na construção da credibilidade dos jornais, algo que só é discutido por uma autora brasileira (LISBOA, 2012). Ao mesmo tempo, há, entre os documentos analisados, muitas pesquisas que estudam o editorial junto de outros gêneros jornalísticos, sem uma discussão particular sobre as peculiaridades do texto. 
No caso brasileiro, alguns periódicos, como Folha de S. Paulo e O Globo são frequentemente estudados, enquanto as produções locais aparecem raramente, especialmente, se não estiverem no Sudeste. A quantidade de teses e dissertações produzidas, junto ao alto número de ensaios recorrentes neste estudo e os vieses que ainda podem ser abordados, indica que a pesquisa sobre editoriais ainda não está completamente consolidada ou saturada de trabalhos.

É importante reconhecer as limitações do levantamento feito por este trabalho. Provavelmente, se outras bases de dados tivessem sido acionadas, os resultados poderiam ser alterados. Defende-se, porém, a relevância do Portal de Periódicos da Capes e da Biblioteca Digital de Teses e Dissertações, constituindo duas fontes de pesquisa representativas.

\section{Notas}

[1] As referências dos trabalhos que compõem o corpus deste artigo podem ser encontradas em http://bit.ly/1zZqouJ.

[2] Como isto só aconteceu, praticamente, em informações sobre o corpus ou sobre as técnicas metodológicas, era suficiente procurar diretamente na seção de estratégias metodológicas para encontrar as informações ausentes do resumo ou da introdução.

[3] Como o mesmo trabalho pode abordar periódicos de lugares diferentes, a soma das ocorrências ultrapassa 110, que é o número de documentos analisados.

[4] Em 2013, a Folha teve uma média de circulação de paga de 294.811 exemplares, sendo o segundo colocado em tiragem no Brasil. O Globo é o terceiro, com 267.542 exemplares diários, seguido por O Estado de S. Paulo, com 234.863 jornais por dia. Disponível em <http://www.anj.org.br/maiores-jornais-do-brasil >. Acesso em 23 out 2014.

[5] Disponível em <http://www.anj.org.br/maiores-jornais-do-brasil >. Acesso em 23 out 2014 .

\section{Referências}

ARMAÑANZAS, Emy; NOCÍ, Javier Díaz. Periodismo y argumentación. Géneros de opinión. Universidad del País Vasco, 1996.

BELTRÃO, Luiz. Jornalismo opinativo. Porto Alegre: Sulina, 1980.

CAPELATO, Maria Helena; PRADO, Maria Lígia. O bravo matutino: imprensa e ideologia no jornal O Estado de S. Paulo. São Paulo: Alfa-ômega, 1980. 
CARREIRO, Rodrigo. O que há de política no Facebook? Análise do perfil de uma área de pesquisa emergente. In Seminário de Pesquisadores do Centro de Estudos Avançados em Democracia, 2014.

COUTINHO, Aline; MIGUEL, Luis Felipe. A crise e suas fronteiras: oito meses de mensalão nos editoriais dos jornais. In Opinião Pública, v. 13, p. 97-123, 2007.

FERREIRA, Norma Sandra de Almeida. As pesquisas denominadas "Estado da Arte". In Educação \& Sociedade, v. 23, n79, p. 257-272, 2002.

HALLOCK, Steven. M. Editorial and Opinion. Praeger: Westport, 2007.

IZADI, Foad; SAGHAYE-BIRIA, Hakimeh. A Discourse Analysis of Elite American Newspaper Editorials: The Case of Iran's Nuclear Program. In Journal of Communication Inquiry, v. 31, n. 2, p. 140-165, 2007.

MELO, José Marques. A opinião no jornalismo brasileiro. Petrópolis: Vozes, 1985.

MONT'ALVERNE, Camila; MARQUES, Francisco Paulo Jamil. Jornalismo Político e Imagem Pública: Dilma Rousseff nos editoriais do jornal O Estado de S. Paulo. In Contracampo, Niterói, v. 28, n. 3, p. 93-115, 2013.

MORAES, Cláudia Herte de. Parcialidade alardeada: notas sobre a importância da opinião no jornalismo. Disponível em <http://tinyurl.com/ad48hhe >. Acesso em:16 dez. 2017

RUBIM, Albino. Políticas culturais do governo Lula / Gil: desafios e enfrentamentos. In Revista Intercom, São Paulo, v. 31, n. 1, p. 183-203, 2008.

VERMELHO, Sônia Cristina; AREU, Graciela Inês Presas. Estado da arte da área de educação e comunicação em periódicos brasileiros. In Educação \& Sociedade, Campinas, v. 26, n. 93, p. 1413-1434, 2005. 